\title{
Currículo e Relações Étnico-Raciais: a identidade da criança negra na Educação Infantil na Amazônia Bragantina
}

\author{
Daquel Atmorim dos Santos*
}

\section{RESUMO}

Este estudo analisa o Currículo e as Relações Étnico-Raciais na Educação Infantil, com foco na identidade da criança negra, a partir das ações realizadas no Projeto de Extensão da Universidade Federal do Pará, Campus Universitário de Bragança sobre Formação de Professores para a Educação das Relações Étnico-Raciais e para o Ensino de História e Cultura Afro-Brasileira e Africana na Educação Básica em Bragança-PA e do Seminário de Educação Infantil sobre o Brincar, criar e inovar: refletindo o currículo e práticas educativas na Educação Infantil, realizado em parceria com a Secretaria Municipal de Educação de Bragança-PA. O referencial teórico-metodológico baseia-se em Cavalleiro (2006), Coelho (2009) e Santos (2009) para a discussão sobre relações étnico-raciais e Educação Infantil e para a incursão sobre identidade negra nos balizamos em Gomes (2002). Os resultados do estudo revelam que os professores a partir do Projeto de Extensão e de suas atividades na escola desenvolvem práticas pedagógicas voltadas para afirmação da identidade da criança negra. No entanto, elas se intensificam, sobretudo no mês que celebra a consciência

\footnotetext{
* Doutorado e Mestrado em Educação pela Universidade Federal do Pará (UFPA). Professora Adjunta A da Universidade Federal do Pará, Campus Universitário de Bragança, Faculdade de Educação. Professora do Programa de Pós-Graduação em Linguagens e Saberes na Amazônia (PPLSA). Pesquisadora do Núcleo de Estudos e Pesquisa sobre Formação de Professores e Relações Étnico-Raciais (GERA/UFPA). Diretora das Áreas Acadêmicas da Associação Brasileira de Pesquisadores Negros - ABPN (2017-2018). Associada a ANPED - Associação Nacional de Pós-Graduação e Pesquisa em Educação e ABPN. Graduada em Pedagogia pela Universidade da Amazônia (UNAMA). E-mail: rakelamorim@ yahoo.com.br rakelamorim@ufpa.br
} 
negra. Concluímos que as práticas pedagógicas antirracista necessitam ser inserido, no: projeto pedagógico, currículo escolar, planejamento de ensino, instrumentos didáticopedagógicos e, sobretudo nas brincadeiras e interações das crianças da Educação Infantil, pois podem contribuir para a construção da identidade positiva da criança negra e para subversão de práticas racistas, preconceituosas e discriminatórias. A ausência das relações étnico-raciais no currículo da Educação Infantil pode impedir a promoção de boas relações étnicas e contribuir para o silêncio que envolve as relações étnico-raciais nas diversas instituições sociais, inclusive a escola.

Palavras-chave: Currículo. Relações Étnico-Raciais. Identidade Negra. Educação Infantil.

\section{ABSTRACT}

This study analyzes the Curriculum and Ethnic-Racial Relations in Early Childhood Education, focusing on the identity of the black child, based on the actions carried out in the Extension Project of the Federal University of Pará, Bragança University Campus on Teacher Education for Ethnic-Racial Relations and for the Teaching of Afro-Brazilian and African History and Culture in Basic Education in Bragança-PA and the Seminar on Early Childhood Education on Creating, Creating and Innovating: Reflecting Curriculum and Educational Practices in Early Childhood Education, held in partnership with the Municipal Department of Education of Bragança-PA. The theoretical-methodological framework is based on Cavalleiro (2006), Coelho (2009) and Santos (2009) for the discussion on ethnic-racial relations and Early Childhood Education and for the incursion on black identity in the beacons in Gomes (2002) . The results of the study reveal that teachers from the Extension Project and their activities at school develop pedagogical practices aimed at affirming the identity of the black child. However, they intensify, especially in the month that celebrates black consciousness. We conclude that antiracist pedagogical practices need to be included in the pedagogical project, school curriculum, teaching planning, didactic-pedagogical instruments and, above all, in the games and interactions of children in Early Childhood Education, since they can contribute to the positive identity of the black child and for the

@rquivo Brasileiro de Educação, Belo Horizonte, v. 6, n. 14, mai-ago, 2018. 
subversion of racist, prejudiced and discriminatory practices. The absence of ethnic-racial relations in the curriculum of Early Childhood Education can impede the promotion of good ethnic relations and contribute to the silence that surrounds ethnic-racial relations in various social institutions, including schools.

Keywords: Curriculum. Ethnic-Racial Relations. Black Identity. Child education.

\section{INTRODUÇÃO}

O estudo analisa o Currículo e as Relações Étnico-Raciais na Educação Infantil, com foco na identidade da criança negra. Esta pesquisa surge a partir do Projeto de Extensão da Universidade Federal do Pará, Campus Universitário de Bragança sobre Formação de Professores para a Educação das Relações Étnico-Raciais e para o Ensino de História e Cultura AfroBrasileira e Africana na Educação Básica em Bragança-PA' e do Seminário de Educação Infantil sobre o Brincar, criar e inovar: refletindo o currículo e práticas educativas na Educação Infantil2, realizado com o escopo de refletir acerca da proposta curricular para a Educação Infantil da Rede Municipal de Ensino de Bragança-PA.

A inserção da Educação Infantil, como primeira etapa da Educação Básica, não só se configura como um grande avanço das políticas públicas para a infância; mas aponta também para a transição de uma tradição de assistência para a definição do direito da criança de zero a cinco anos a uma educação pública de qualidade. Nesse sentido, os professores da Educação Infantil buscam formas de reconhecer as especificidades e as peculiaridades que envolvem as relações estabelecidas pelas crianças com

\footnotetext{
${ }^{1}$ Projeto de Extensão Coordenado pela Prof ${ }^{a}$ Dr $^{a}$ Raquel Amorim dos Santos em parceria com a Secretaria Municipal de Educação, por meio da Coordenadoria da Promoção da Igualdade Racial, sob a Coordenação da Prof ${ }^{a}$ MSc. Elizabeth Conde de Morais.

${ }^{2}$ Seminário realizado pela Secretaria Municipal de Educação de Bragança-PA, por meio da Coordenação de Educação Infantil sob a orientação da Prof ${ }^{a}$ Rosália Saraiva Galvão e Márcia Saviczki Pinho.
} 
- mundo que as circunda e os sentidos que atribuem às suas experiências (SANTOS, 2015).

As experiências das crianças também devem voltar-se para o respeito às diferenças étnico-raciais. Nesse sentido, a Lei n. ${ }^{\circ}$ 10.639/2003 ampliada pela Lei 11.645/2008 que altera a Lei de Diretrizes Bases da Educação Nacional (LDB n. ${ }^{\circ}$ 9.394/96) e torna obrigatória a história e cultura afrobrasileira, africana, bem como inclui a história e cultura dos povos indígenas no currículo oficial das escolas de Educação Básica e Ensino Superior brasileira, possibilita mudanças diante da história, de forma a desmistificar os conteúdos acerca da África, da diáspora africana, dos negros brasileiros, e incluir uma dimensão social e cultural necessária à formação de crianças, adolescentes, jovens e adultos (SANTOS, 2009).

Essa legislação compõe um conjunto de dispositivos legais considerados como indutores de uma política educacional voltada para afirmação da diversidade cultural e da concretização de uma educação das relações étnico-raciais nas instituições de ensino como mecanismo reparador das distorções históricas que as narrativas hegemônicas fizeram prosperar na educação do país e, consequentemente, no imaginário social (SANTOS, 2009; COELHO, 2009).

Pensar a criança no contexto da Educação Infantil é compreendê-la como centro do planejamento curricular, como sujeito histórico e de direitos que, nas interações, relações e práticas cotidianas que vivência, constrói sua identidade pessoal e coletiva, brinca, imagina, fantasia, deseja, aprende, observa, experimenta, narra, questiona e constrói sentidos sobre a natureza e a sociedade, produzindo cultura (BRASIL, 2010).

O estudo dialoga com o currículo da Educação Infantil, no sentido de perscrutar acerca da construção da identidade da criança negra a partir de diferentes práticas pedagógicas realizadas no âmbito de escolas de Educação Infantil, considerando as Diretrizes Curriculares Nacionais para a Educação Infantil (DCNEI), Estrutura Curricular para a Educação Infantil da 
Rede Municipal de Bragança-PA de 2017 (de 0 a 3 anos) e as Diretrizes Curriculares Nacionais para a Educação das Relações Étnico-Raciais e para o Ensino de História e Cultura Afro-Brasileira e Africana (DCNERER).

Assim, no primeiro momento discorremos sobre o currículo e as relações étnico-raciais na Educação Infantil e no segundo abordamos acerca da identidade da criança negra a partir de práticas pedagógicas desenvolvidas no Projeto de Extensão da UFPA sobre a Formação de Professores para a Educação das Relações Étnico-Raciais e seus desdobramentos no currículo da Educação Infantil.

\section{PERCURSO METODOLÓGICO}

A abordagem adotada para esta pesquisa é qualitativa (MINAYO, 2001). Utilizamos a pesquisa bibliográfica como ponto de partida para a compreensão da produção intelectual na área. O estudo foi realizado a partir das atividades do Projeto de Extensão sobre Formação de Professores e Relações Étnico-Raciais, em parceria com a SEMEd de Bragança-PA, sendo que os alunos são filhos de agricultores e pescadores artesanais, da região.

No universo dos professores da Educação Básica que atuam na Rede Municipal de Ensino de Bragança, Nordeste Paraense, elegeu-se (=60) professores da Educação Infantil, Ensino Fundamental e Modalidade da Educação de Jovens e Adultos que atuavam no Projeto de Extensão da UFPA, dentre eles (=12), professores da Educação Infantil que participaram regularmente da formação continuada em 2017, além de (=3) escolas de Educação Infantil com o escopo de compreender o currículo da Educação Infantil e a educação das relações étnico-raciais com vista a construção positiva da identidade da criança negra. As entrevistas com as professoras da Educação Infantil foram importantes para saber se o currículo desenvolvido na Educação Infantil contempla atividades que visem o enfretamento do racismo, preconceito e discriminação racial e na escola e 
contribui para a identidade de crianças negras no universo escolar. Utilizamos para incremento dos registros da pesquisa a fotografia como fonte de conhecimento e informação complementar.

Os sujeitos do estudo foram professoras da Educação Infantil que participaram das ações extensionistas do Projeto, tendo como principais instrumentos para a produção e coleta de dados a observação, práticas pedagógicas de professoras da Educação Infantil acerca das relações étnico-raciais e registros fotográficos.

\section{CURRÍCULO E RELAÇÕES ÉTNICO-RACIAIS NA EDUCAÇÃO INFANTIL}

No âmbito da Educação Infantil o currículo busca articular as experiências e os saberes das crianças com os conhecimentos que fazem parte do patrimônio cultural, artístico, científico e tecnológico da sociedade por meio de práticas planejadas e permanentemente avaliadas que estruturam o cotidiano das instituições (BRASIL, 2010).

Um currículo, portanto, vivenciado com as crianças a partir de seus saberes, manifestações culturais, de modo a considerar as especificidades, interesses singulares, potencialidades e coletivos das crianças, bem como seus aspectos motores, afetivos, cognitivos e linguísticos, os quais integram-se e estão em permanente mudança.

De acordo com as Diretrizes Curriculares Nacionais para a Educação Infantil (DCNEI) o currículo é concebido como um conjunto sistematizado de práticas culturais no qual se articulam as experiências e saberes das crianças, de suas famílias, dos profissionais e de suas comunidades de pertencimento e os conhecimentos que fazem parte do patrimônio cultural, artístico, científico e tecnológico, baseado em princípios básicos - éticos, políticos, estéticos (BRASIL, 2010).

A Estrutura Curricular para a Educação Infantil da Rede Municipal de Bragança foi elaborada com base na Proposta Curricular para a 
Educação Infantil do Município de Bragança/PA (2012), de acordo com as Diretrizes Curriculares Nacionais para a Educação Infantil (Resolução CEN/CEB No 5/2009). Ambas compreendem o Currículo como práticas sociais e a criança como centralidade na organização das propostas curriculares em que as brincadeiras e interações são aspectos fundamentais. A Estrutura Curricular pretende atuar como material de apoio ao professor. Nesse sentido, não o considera pronto, acabado e estanque.

A estrutura Curricular da Educação Infantil de Bragança-PA, por sua vez apresenta quatro eixos norteadores para a organização curricular própria e singular das instituições escolares que comportem a Educação Infantil, quais sejam: experiências de descoberta e exploração das linguagens, experiências investigativas sobre si e sobre $O$ mundo, experiências de exploração do cotidiano e experiências de valorização da expressividade e faz de conta, que podem ser ampliadas de acordo com as necessidades específicas de cada comunidade escolar (GALVÃO, 2017).

As práticas pedagógicas, nesse sentido devem garantir experiências diversas, sobretudo o conhecimento de si e do mundo por meio das experiências sensoriais, expressivas e corporais para movimentação ampla, expressão da individualidade e respeito pelos ritmos e desejos da criança. Nesse sentido, é importante a imersão nas diferentes linguagens e domínio de gêneros e formas de expressão (gestual, verbal, plástica, dramática e musical) e as diferentes experiências da criança e sua apreciação e interação com a linguagem oral e escrita e convívio com diferentes suportes e gêneros textuais, orais e escritos.

$\mathrm{Na}$ Educação Infantil a criança vivencia diferentes experiências voltadas para a exploração do cotidiano que possibilita recriar, em contextos significativos, relações quantitativas, medidas, formas e orientações espaço/temporais. Experiências de valorização da expressividade e faz de conta por meio de narrativas, movimento (imagem do próprio corpo, equilíbrio e coordenação, gestos, ritmos corporais). 
Experiências para ampliar a confiança e a participação das crianças nas atividades individuais e coletivas, de modo a contribuir para a aprendizagem da autonomia, nas ações de cuidado pessoal, autoorganização, saúde e bem-estar.

As vivências éticas e estéticas com outras crianças e grupos culturais favorecem a identidade e a diversidade, a curiosidade, a exploração, o encantamento, o questionamento, a indagação e o conhecimento em relação ao mundo físico e social, ao tempo e à natureza. Também é importante considerar o relacionamento e interação entre as crianças durante as manifestações de música, artes plásticas e gráficas, cinema, fotografia, dança, teatro, poesia e literatura.

Para Kramer (1999, pp.19-20) na "[...] experiência a ação que é contada a outro, compartilhada, tornando-se infinita. Esse caráter histórico, de permanência, de ir além do tempo vivido, torna-se coletiva, constitui a experiência". A construção da autoestima e da identidade da criança e do grupo é processual. As brincadeiras, por exemplo, são formas de expressão, são também oportunidades para a manifestação da individualidade de cada criança, de sua identidade, porque cada uma tem uma singularidade que deve ser respeitada.

Entender a construção da identidade da criança negra perpassa por entender como são estabelecidas as relações sociais na família, escola, grupo de amigos e na igreja, entre outros. Para além do caráter estético, o corpo e o cabelo tratam do caráter simbólico e identitário da cultura negra. Portanto, a cultura negra é construída não só a partir do olhar que o negro tem de si, mas também da relação que ele tem com o olhar do outro sobre ele, não só o que é refletido no espelho importa, mas a sociedade também atua como um espelho.

A interação sob a ótica das crianças perpassa pela ação que se exerce mutuamente na relação entre crianças e adultos (essenciais para dar riquezas e complexidade às brincadeiras), crianças entre si (com idades 
iguais ou diferentes), bem como crianças e os brinquedos (por meio das diferentes formas de brincar com os objetos/brinquedos), crianças e o ambiente (a organização do ambiente facilita ou dificulta a ação de brincar) e crianças, as instituições e as famílias - tais relações possibilitam vínculos que favorecem um clima de respeito mútuo e confiabilidade, gerando espaços para o trabalho colaborativo e a identificação da cultura popular da criança e de sua família, de suas brincadeiras e brinquedos preferidos.

Assim, as interações sejam elas entre crianças e os adultos, ou mesmo entre si, seus brinquedos, o ambiente, instituições e famílias contribui para o reconhecimento das diferenças.

\section{A IDENTIDADE DA CRIANÇA NEGRA A PARTIR DE AÇÕES EXTENSIONISTAS E PRÁTICAS PEDAGÓGICAS NA EDUCAÇÃO INFANTIL}

Essa seção objetiva apresentar as práticas pedagógicas de professores da Educação Infantil para a construção da identidade da criança negra, realizada a partir do Projeto de Extensão sobre Formação de Professores para a Educação das Relações Étnico-Raciais e para o Ensino de História e Cultura Afro-Brasileira e Africana na Educação Básica em Bragança-PA, financiada pela Universidade Federal do Pará (UFPA), por meio da PróReitora de Extensão (PROEX/UFPA) e em parceria com a Secretaria Municipal de Educação de Bragança (SEMED). Essas atividades buscam atender as determinações das Diretrizes curriculares nacionais para a educação infantil (DCNEl), Diretrizes Curriculares Nacionais para a Educação das Relações Étnico-Raciais (DCNERER) e Estrutura Curricular para a Educação Infantil da Rede Municipal de Bragança-PA (de 0 a 3 anos).

De acordo com as DCNEl, as propostas pedagógicas das instituições de Educação Infantil deverão prever condições para o trabalho coletivo e para a organização de materiais, espaços e tempos que assegurem:

@rquivo Brasileiro de Educação, Belo Horizonte, v. 6, n. 14, mai-ago, 2018. 
A apropriação pelas crianças das contribuições histórico-culturais dos povos indígenas, afrodescendentes, asiáticos, europeus e de outros países da América [...]. O reconhecimento, a valorização, o respeito e a interação das crianças com as histórias e as culturas africanas, afro-brasileiras, bem como o combate ao racismo e à discriminação (BRASIL, 2010, p.20-21).

Pensar as práticas pedagógicas que contemplem a diversidade étnico-racial exige aporte teórico específico para o trato com as relações étnico-raciais, bem como formação inicial e continuada de professores com vista a valorização da diversidade, a fim de contribuir para superar a desigualdade étnico-racial presente na educação escolar brasileira, nos diferentes níveis e modalidades de ensino, visando as reparações, reconhecimento e valorização da identidade negra (SANTOS, 2009).

Para Gomes (2002, p.2) a identidade negra é compreendida como:

[...] uma construção social, histórica e cultural repleta de densidade, de conflitos e de diálogos. Ela, implica a construção do olhar de um grupo étnico/racial ou de sujeitos que pertencem a um mesmo grupo étnico/racial sobre si mesmos, a partir da relação com o outro. (GOMES, 2002, p. 2).

Um olhar que, quando confrontado com o do outro, volta-se sobre si mesmo, pois só o outro interpela nossa própria identidade. Cavalleiro (2006, p.19) assegura que "[...] a identidade resulta da percepção que temos de nós mesmos, advinda da percepção como os outros nos veem". Assim, a identidade é concebida como um processo dinâmico que possibilita a construção gradativa da personalidade no decorrer da existência do indivíduo (CAVALLEIRO, 2006).

Para Hall (2001), a identidade desconstrói a concepção de identidades fixas, iluministas, imutáveis, mas corrobora para a concepção de identidade processual, construídas nos constitutivos da linguagem, cultura, história, religião, entre outros, comuns aos membros de um grupo social (SANTOS, 2009).

@rquivo Brasileiro de Educação, Belo Horizonte, v. 6, n. 14, mai-ago, 2018. 
A construção da identidade negra foi temática desenvolvida no Projeto de Extensão sobre Formação de Professores e Relações ÉtnicoRaciais. A oficina realizada com o tema Relações Étnico-Raciais e Ludicidade ${ }^{3}$ contemplou a confecção de bonecas Abayomi, como símbolo de resistência, tradição e poder feminino, cujo objetivo foi resgatar a memória e identidade negra, valorizando a diversidade cultural na Educação Infantil.

O termo Abayomi, significa 'Encontro precioso', em lorubá, uma das maiores etnias do continente africano cuja população habita parte da Nigéria, Benin, Togo e Costa do Marfim. Segundo a história as bonecas Abayomi serviram para acalentar os filhos das mães africanas durante as terríveis viagens a bordo dos tumbeiros (navio de pequeno porte que realizava o transporte de escravos entre África e Brasil). As mães africanas rasgavam retalhos de suas saias e a partir deles criavam pequenas bonecas, feitas de tranças ou nós, que serviam como amuleto de proteção.

A partir da formação os professores foi realizada a oficina com bonecas Abayomi como visualizamos na fotografia 1 abaixo:

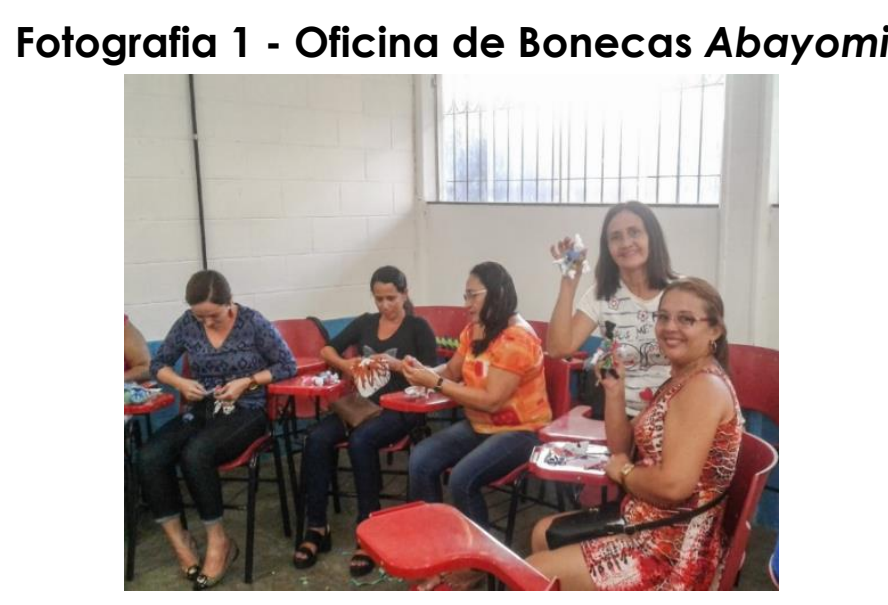

Fonte: Arquivo do Projeto de Extensão (2017)

\footnotetext{
${ }^{3}$ Oficina realizada pela Prof ${ }^{a}$ Simei Santos Andrade da Escola de Teatro e Dança da Universidade Federal do Pará-UFPA.
}

@rquivo Brasileiro de Educação, Belo Horizonte, v. 6, n. 14, mai-ago, 2018. 
A partir das atividades extensionistas, a Creche Municipal Ana Souza de Oliveira, entre outras escolas confeccionou com as crianças do Pré I, a boneca Abayomi como símbolo de resistência negra como visualizamos na fotografia 2. Nela, podemos perceber a alegria das crianças, o entusiasmo, a brincadeira, a convivência e a interação com outras crianças.

\section{Fotografia 2 - Oficina de boneca Abayomi na Creche Municipal Ana Souza}

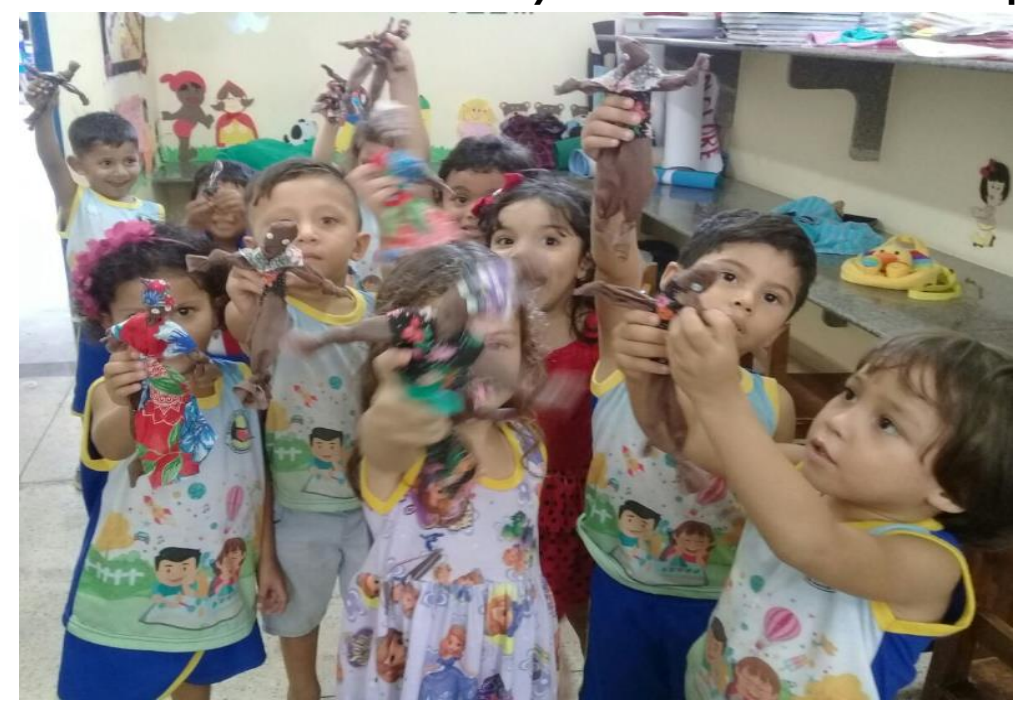

Fonte: Arquivo da Creche Municipal Ana Souza

A oficina sobre jogos de mancala, também foi outra atividade realizada pelos professores na formação continuada acerca da educação para as relações étnico-raciais na área de conhecimento de Matemática, cujo objetivo foi contribuir para o desenvolvimento do raciocínio lógico e matemático das crianças.

A palavra mancala origina-se do árabe naqaala, que significa mover. Com o tempo esse termo passou a ser usado pelos antropólogos para designar uma série de jogos disputados num tabuleiro com várias cavidades e com o princípio de distribuição de peças. A forma pela qual este se realiza está intimamente associada à semeadura. Este fato, aliado ao local de origem, leva alguns a crê que os jogos da família mancala são talvez os mais antigos do mundo (MACEDO; PETTY; PASSOS, 2007).

@rquivo Brasileiro de Educação, Belo Horizonte, v. 6, n. 14, mai-ago, 2018. 
Câmara e Santos (2017) relatam que os jogos africanos, em particular, os de tabuleiro, conhecidos como Mancalas são também chamados de jogos de semeaduras ou jogos de contagem e captura e é um jogo exclusivamente voltado para o raciocínio lógico e matemático. Santos (2008, p. 15) enfoca que "[...] o Mancala revela uma íntima relação entre homem e Mãe Terra: "semeaduras e colheitas" que simbolizam o movimento das peças, dentro de uma complexidade próxima do xadrez".

É jogado habitualmente, com pequenas pedras ou sementes. A movimentação de peças tem um sentido de "semeaduras" e "colheita". Cada jogador é obrigado a recolher sementes (que neste momento não pertence a nenhum dos jogadores) depositadas numa "casa" e com elas semear suas casas do tabuleiro, bem como as casas do adversário. Seguindo as regras, em dado momento o jogador faz a "colheita" de sementes que passam a ser suas. Ganha quem obtiver mais sementes, ao final do jogo (SANTOS, 2008, p.14).

O uso de jogos da família Mancala foi utilizada na formação continuada de professores da SEMED, uma vez que esse jogo pode ser usado em toda etapa escolar, desde a Educação Infantil até o Ensino Médio, cabendo ao professor (condutor do processo) fazer as adaptações de acordo com nível de escolaridade, ou seja, diminuir ou aumentar o grau de dificuldade, alterando as regras ou até mesmo o tabuleiro de acordo com o número de concavidades, o que resulta num grau maior de complexidade durante 0 jogo. Abaixo apresentamos a fotografia 3 relacionada a oficina de mancala.

@rquivo Brasileiro de Educação, Belo Horizonte, v. 6, n. 14, mai-ago, 2018. 
Fotografia 3 - Oficina de Jogo de Mancala

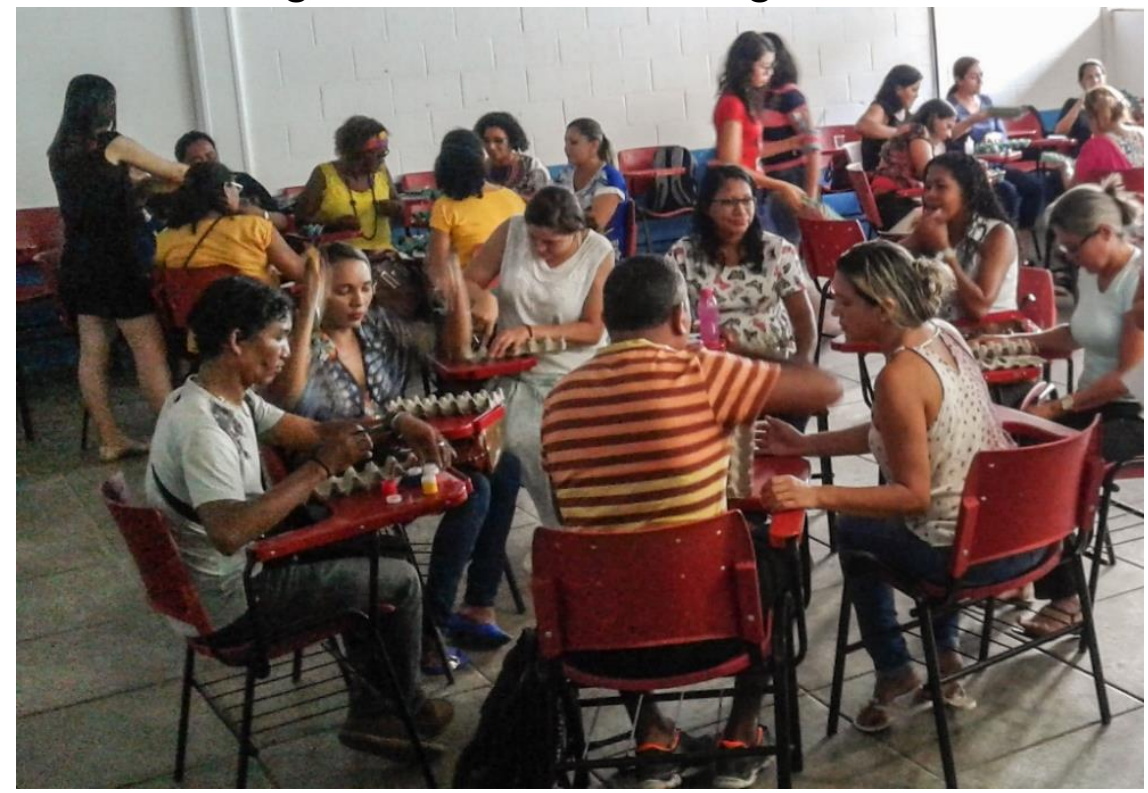

Fonte: Arquivo Projeto de Extensão (2017).

Essa oficina proporcionou aos professores movimentos calculados, concentração, antecipação da jogada e das consequências dela em todo o movimento do tabuleiro, exigindo uma parcela de esforço individual. A partir desse jogo os professores descobriram as melhores estratégias para suas jogadas, além da interação, interesse e participação no grupo.

O ato de brincar está, indiscutivelmente, presente no cotidiano de toda criança, tornando-se uma necessidade básica. A criança precisa ter oportunidade de vivenciar situações ricas e desafiadoras, as quais são proporcionadas pelos jogos, brinquedos e brincadeiras como recurso pedagógico.

Assim, é possível desenvolver na Educação Infantil os jogos de mancala, pois contribui para estabelecer aproximações a algumas noções matemáticas presentes no cotidiano da criança, como: contagem, relações espaciais, utilização da contagem oral, de noções de quantidade, de tempo e de espaço em jogos, brincadeiras e músicas junto com o professor e nos diversos contextos nos quais as crianças reconheçam essa utilização como necessária, conforme assegura a Estrutura Curricular da Educação 
Infantil de Bragança-PA.

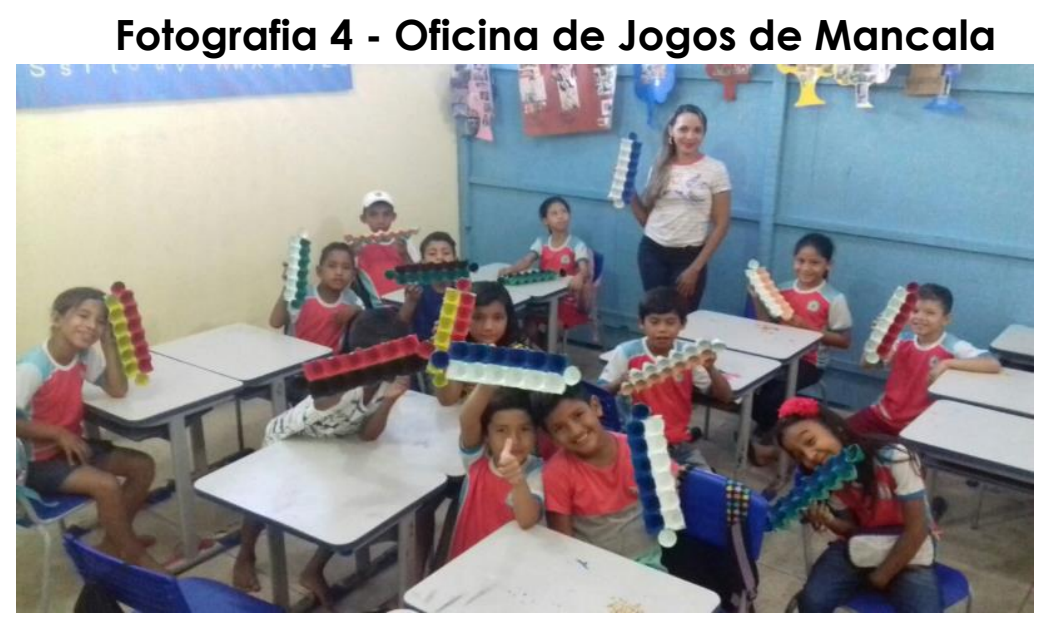

Fonte: Arquivo da Escola (2017)

Os professores desenvolveram a oficina com as crianças sobre os jogos de mancala, brincaram entre si, com sensibilidade, criatividade e de forma lúdica, desenvolvendo práticas pedagógicas que possibilitaram as interações e brincadeiras como eixos norteadores do Currículo da Educação Infantil (BRASIL, 2010).

Além das oficinas com a boneca Abayomi e jogos de mancala, ainda foi desenvolvido, dentre outras atividades a contação de histórias infantis ${ }^{4}$ voltada para temática étnico-racial como visualizado na fotografia 5.No primeiro momento dessa oficina foi realizado estudo teórico sobre a contação de histórias infantis, com base no texto "Tradição viva" de Hampaté Bâ, em seguida foram efetivadas atividades práticas, cuja metodologia foi a organização de grupo de trabalhos, leitura e discussão de livros infantis sobre as relações étnico-raciais e dramatização de histórias, como visualizamos na Fotografia 5.

\footnotetext{
${ }^{4}$ Oficina realizada pela Prof ${ }^{a}$ Msc. Andréa de Lima Souza Cozzi, contadora de histórias e Técnica Municipal de Bibliotecas Escolares da SEMEC.
}

@rquivo Brasileiro de Educação, Belo Horizonte, v. 6, n. 14, mai-ago, 2018. 


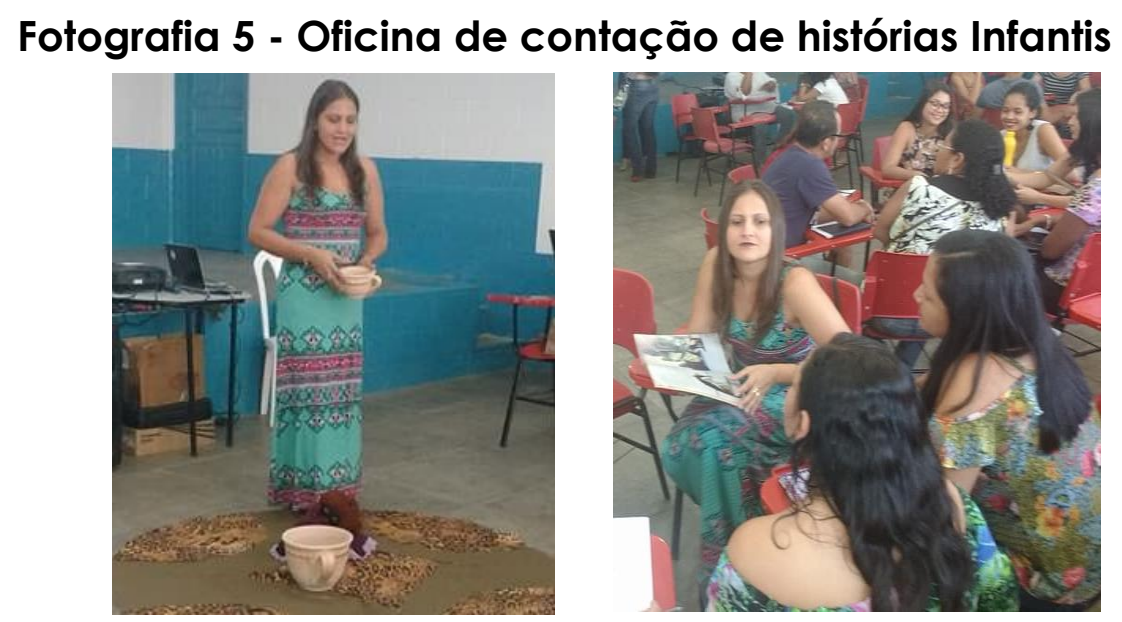

Fonte: Arquivo do Projeto de Extensão (2017).

Para Rodrigues (2005) a contação de histórias é atividade própria de incentivo à imaginação e o trânsito entre o fictício e o real. Os fatos, as cenas e os contextos são do plano do imaginário, mas os sentimentos e as emoções transcendem a ficção e se materializam na vida real.

A contação de histórias está ligada diretamente ao imaginário infantil. O uso dessa ferramenta incentiva não somente a imaginação, a brincadeira, a interação, mas a ampliação do vocabulário, da narrativa, da cultura e contribui para a construção positiva da identidade da criança negra na escola, como observamos em algumas atividades realizadas com as crianças da Educação Infantil.

\section{Fotografia 6 e 7 - Contação de histórias Infantis Menina bonita do laço de fita}
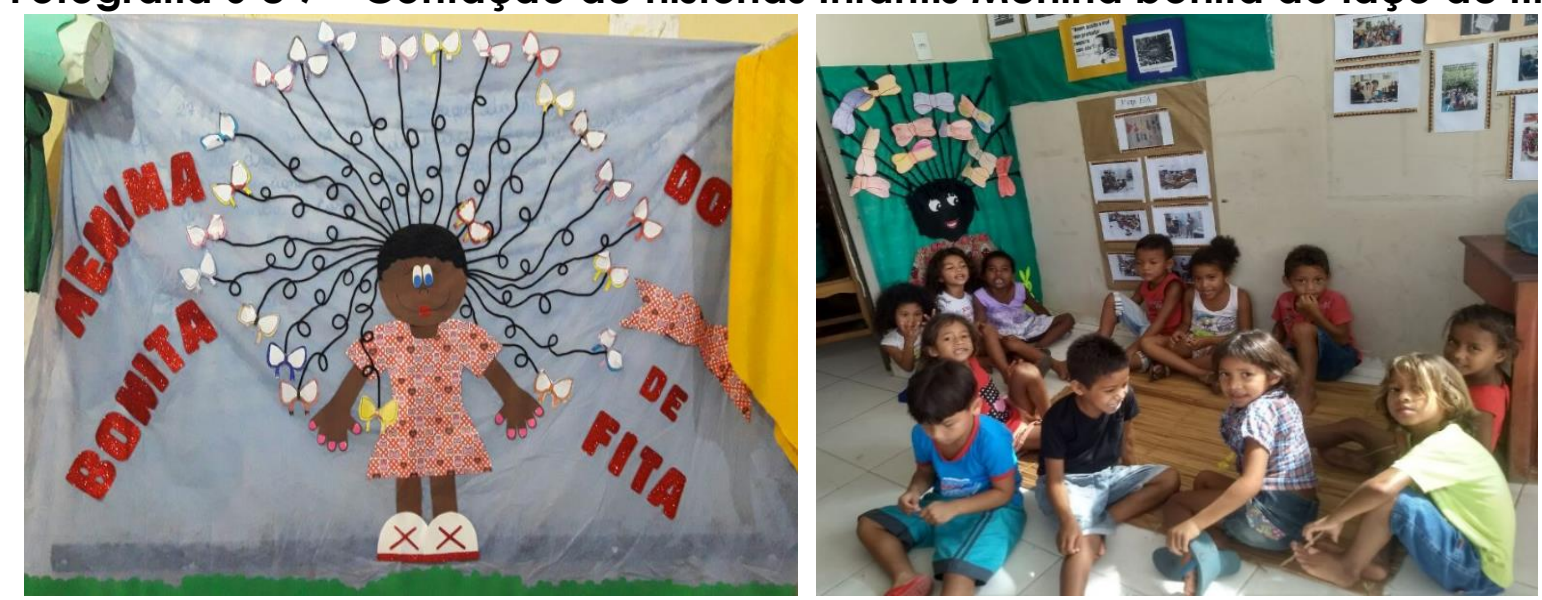

Fonte: Acervo da Escola América Pinheiro de Brito

@rquivo Brasileiro de Educação, Belo Horizonte, v. 6, n. 14, mai-ago, 2018. 
A história da Menina bonita do laço de fita de Ana Maria Machado é um clássico da literatura e foi utilizado na Escola de Educação Infantil com os objetivos de apropriar-se de valores como o respeito a si próprio e ao outro, elevar a autoestima das crianças negras; bem como promover discussões sobre os valores humanos, da beleza negra e da diversidade e respeitar as diferenças.

A Creche Municipal Ana Souza de Oliveira, também realizou com os alunos a contação de histórias Infantis sobre Conto Africano, a partir do livro: A menina e o tambor de Sônia Junqueira e desenho de Mariângela Haddad, enfatizando a origem do tambor e brincadeiras envolvendo a sonoridade e a musicalidade desse instrumento.

\section{Fotografia 8 - Desenhos realizados pelas crianças do Pré I}
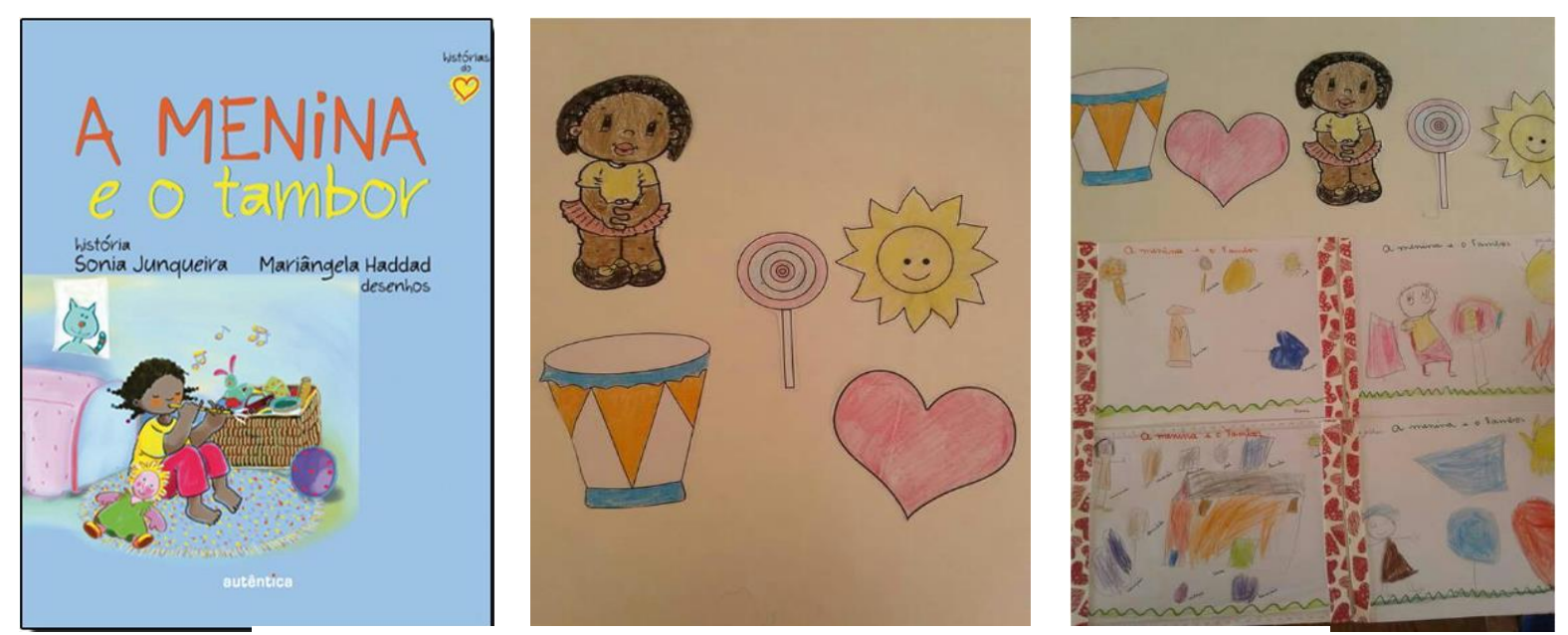

Fonte: Acervo da Creche Municipal Ana Souza

As criaças, ainda realizaram várias atividades sobre a história da Menina e o tambor,brincaram, interagiram, produziram, [re]contaram suas histórias a partir de suas interpretações e de seu mundo.

@rquivo Brasileiro de Educação, Belo Horizonte, v. 6, n. 14, mai-ago, 2018. 


\section{Fotografia 9 e 10 -Atividades e [re]contação de histórias infantis (Pré I)}
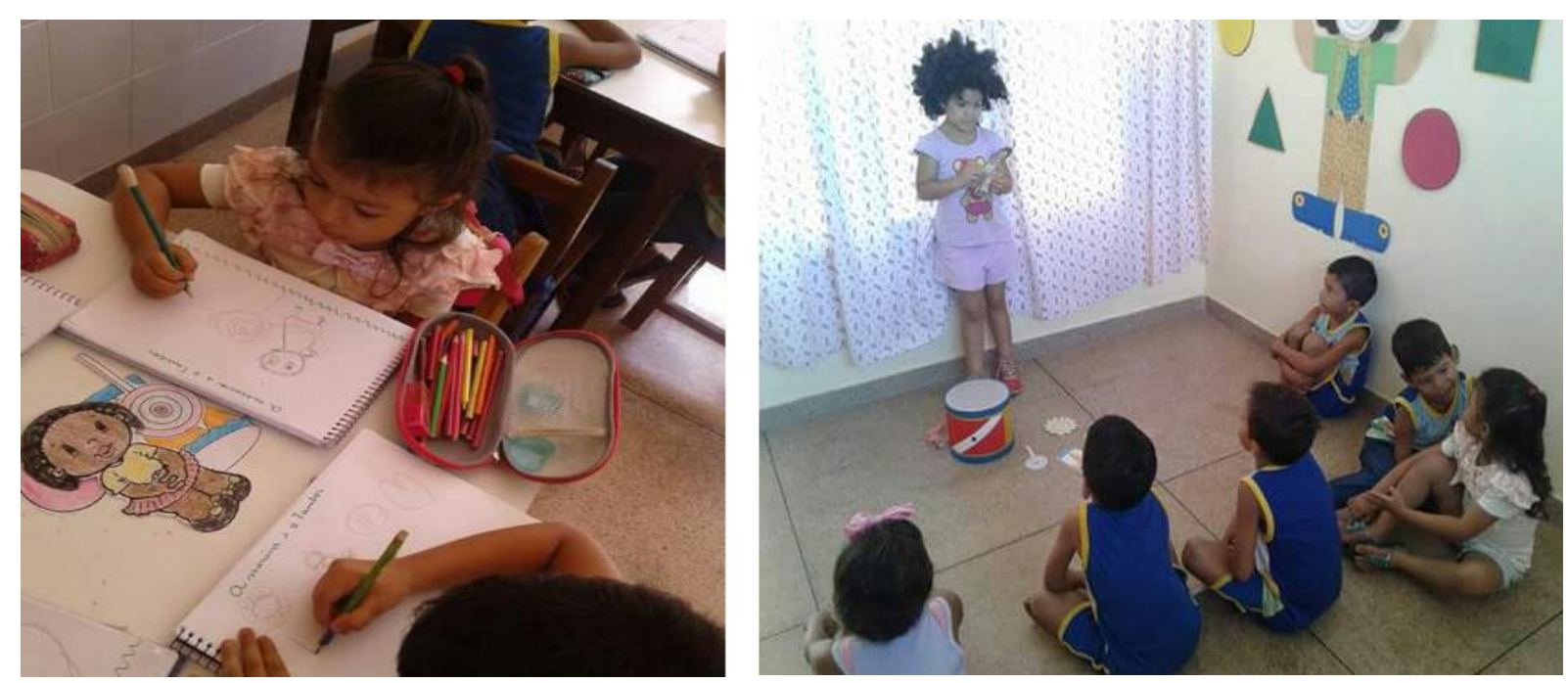

Fonte: Arquivo da Escola de Educação Infantil

As crianças gostam de ouvir vários tipos de histórias e, também, fazer comentários, mas não de ficar apenas ouvindo e caladas. Ao participarem, vão se tornando leitoras, ouvindo, vendo, falando, gesticulando, lendo, desenhando sua própria história e construindo novas histórias. Durante a brincadeira imaginária, as crianças constroem suas histórias, integraram outros textos, usam a linguagem falada. Portanto, ao considerar a contação de histórias como portadora de significados para a prática pedagógica, não se restringe o seu papel somente ao entendimento da linguagem. Preservase seu caráter literário, sua função de despertar a imaginação e sentimentos, assim como suas possibilidades de transcender a palavra.

A partir das práticas pedagógicas de professores no curso de extensão sobre formação e relações étnico-raciais e de sua aplicabilidade nas escolas de Educação Infantil, percebemos que essas atividades podem contribuir para a afirmação da identidade da criança negra, interação, brincadeiras, imaginação; bem como para repensar um currículo descentrado, que contemple a diversidade étnico-cultural e possibilite a compreensão das singularidades e potencialidades de cada criança, podendo contribuir para promover condições de igualdade.

@rquivo Brasileiro de Educação, Belo Horizonte, v. 6, n. 14, mai-ago, 2018. 


\section{CONSIDERAÇÕES FINAIS}

Pensar o currículo na Educação Infantil é compreendê-lo a partir das interações, das brincadeiras, do imaginário, da fantasia, do desejo, da narração e das identidades construídas para afirmação dos sujeitos historicamente invisibilizados. Nesse sentido, o currículo corrobora para práticas que considerem as experiências e os saberes das crianças, uma vez que é concebido como uma produção social e cultural que organiza os conhecimentos, os conteúdos e as experiências a serem vivenciadas pelas crianças na Educação Infantil.

O currículo para a Educação Infantil, portanto precisa contemplar não apenas as áreas de conhecimento, mas, principalmente, atentar para ações de educação e cuidado capazes de proporcionar o desenvolvimento integral das crianças; considerando os aspectos físico, mental, cognitivo, emocional, afetivo e as diferenças no cotidiano da escola e, sobretudo da sala de aula.

Ao analisar as práticas pedagógicas voltadas para educação das relações étnico-raciais na Educação Infantil, os resultados do estudo revelam que as professoras a partir da formação do Projeto de Extensão da UFPA e dos trabalhos já realizados na escola, desenvolvem diferentes práticas de enfrentamento a invisibilidade das relações étnico-raciais no contexto escolar com vista a construção da identidade da criança negra. Mas, percebemos que na maioria das vezes essas atividades se intensificam a partir do mês que celebra a consciência negra.

Concluímos que as práticas pedagógicas antirracistas necessitam ser inseridas nos projetos pedagógicos, currículo escolar, planejamento de ensino, instrumentos didático-pedagógicos e, sobretudo nas brincadeiras e interações das crianças da Educação Infantil, pois podem contribuir para a construção da identidade positiva da criança negra e para subversão de práticas racistas, preconceituosas e discriminatórias. A ausência das relações 
étnico-raciais no currículo da Educação Infantil pode impedir a promoção de boas relações étnicas e contribuir para o silêncio que envolve as relações étnico-raciais nas diversas instituições sociais, inclusive a escola.

\section{REFERÊNCIAS}

BONECAS Abayomi: símbolo de resistência, tradição e poder feminino. [S.I.]: Geledés, 220 mar. 2015. Disponível em: https://www.geledes.org.br/bonecasabayomi-simbolo-de-resistencia-tradicao-e-poder-feminino/. Acesso em: 08 nov. 2017.

BRASIL. Ministério da Educação. Secretaria de Educação Básica. Diretrizes Curriculares Nacionais para a Educação Infantil. Brasília: MEC, SEB, 2010.

BRASIL. Diretrizes curriculares nacionais para a educação das relações étnico-raciais e para o ensino de história e cultura Afro-Brasileira e Africana. Brasília: INEP, 2004.

CÂMARA, Luciene Tavares; SANTOS, Maria Auxiliadora Antunes dos. Mancala, um jogo milenar, contribuindo na alfabetização matemática de jovens e adultos. Brasília: UNB, 2017. Disponível em:

http://www.ucb.br/sites/100/103/tcc/22006/lucienetavaresdacamara.pdf. Acesso em: 11 nov.2017.

CAVALLEIRO, Eliane dos Santos. Do silêncio do lar ao silêncio escolar: racismo, preconceito e discriminação na educação infantil. 5.ed. São Paulo: Contexto: 2006.

COELHO, Wilma de Nazaré Baía. A cor ausente. Belo Horizonte: Mazza Edições, 2009.

GALVÃO, Rosália Saraiva; PINHO, Márcia Saviczki. Estrutura curricular para a educação Infantil da rede municipal de Bragança-PA de 0 a 3 anos.

Secretaria Municipal de Educação. Bragança-PA, 2017.

GOMES, Nilma Lino. Educação e identidade negra. Aletria: revista de estudos de literatura, v. 9, p. 38-47, 2002.

KRAMER, Sonia. Leitura e escrita de professores em suas histórias de vida e formação. Cadernos de Pesquisa, São Paulo, FCC, n. 106, p. 129-157, mar, 1999.

@rquivo Brasileiro de Educação, Belo Horizonte, v. 6, n. 14, mai-ago, 2018. 
HALL, Stuart. A identidade cultural na pós-modernidade. Tradução de Tomaz Tadeu da Silva. Rio de Janeiro: DP\&A editora, 2001.

MACEDO, Lino de; PETTY, Ana Lúcia Sícoli; PASSOS, Norimar Christe. Aprender com jogos e situações-problemas. Porto Alegre: Artmed, 2007.

MINAYO, Maria Cecília de Souza (Org.). Pesquisa social: teoria, método e criatividade. 19. ed. Petrópolis: Vozes, 2001.

RODRIGUES, Edvânia Braz Teixeira. Cultura, arte e contação de histórias. Goiânia: Gwaya, 2005.

SANTOS, Raquel Amorim dos. (In) visibilidade negra: representação social de professores acerca das relações raciais no currículo escolar do Ensino Fundamental em Ananindeua (PA). 2009. Dissertação (Mestrado em Educação) - Instituto de Ciências da Educação, Programa de PósGraduação em Educação Universidade Federal do Pará, Belém, 2009.

SANTOS, Celso José dos. Jogos africanos e a educação matemática: semeando com a família Mancala. Maringá: Secretaria de Estado da Educação, 2008. Disponível em:

http://www.diaadiaeducacao.pr.gov.br/portals/pde/arquivos/121-2.pdf. Acesso em: 11 nov. 2017.

SANTOS, Sandro Vinicius Sales dos. Walter Benjamin e a experiência infantil: contribuições para a educação infantil. Pro-Posições, v. 26, n. 2 (77), p. 223239, maio/ago. 2015. 